\title{
ERRATUM
}

\author{
A. López-Cortés · F. García-Pichel · U. Nübel \\ R. Vázquez-Juárez
}

\section{Cyanobacterial diversity in extreme environments in Baja California, Mexico: a polyphasic study}

Published online: 19 December 2001

(C) Springer-Verlag and SEM 2001

\section{Int. Microbiol (2001) DOI 10.1007/s10123-001-0042-z}

In Fig. 1, the numbers indicating the study sites were missing from the symbols on the map. A corrected map showing the numbers appears on the right.

In the Results section, in the fourth paragraph of the subsection "Morphological descriptions based on natural samples and cultures", 25 genera should be listed (not 24). The genus Microcoleus should appear between Limnothix and Nodularia.

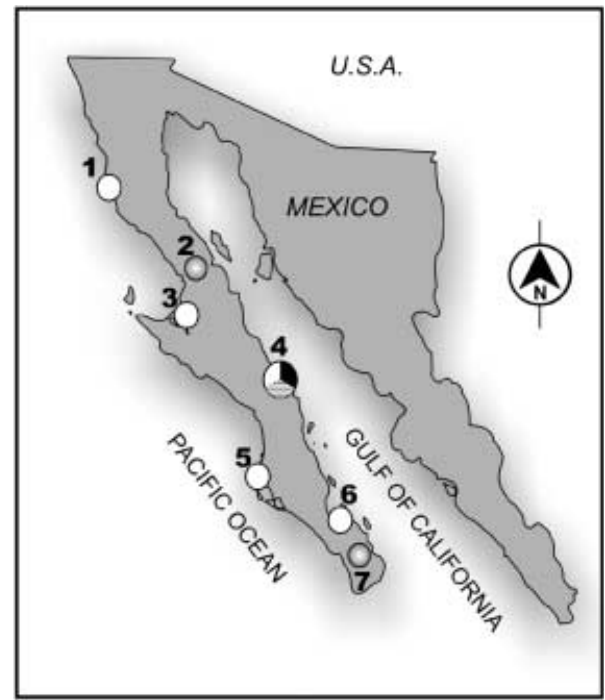

Fig. 1 Map of the study sites, and types of microbial communities. 1 Laguna Figueroa, Baja California Norte (B.C.N.); 2 Cataviña Desert, B.C.N.; 3 Guerrero Negro, Baja California Sur (B.C.S.); 4 Bahia Concepcion, B.C.S.; 5 Bahia Magdalena, B.C.S.; 6 Ensenada de Aripez, B.C.S.; 7 Sierra de La Laguna B.C.S. White circles Hypersaline ecosystems, gray circles soil microbiotic crusts, dotted circle hydrothermal springs, black circles sea-bottom environments

The online version of the original article can be found at http:// dx.doi.org/10.1007/s10123-001-0042-z

A. López-Cortés $(\bowtie) \cdot R$. Vázquez-Juárez Molecular Microbial Ecology Laboratory,

The Center for Biological Research of the Northwest, CIBNOR, Mar Bermejo 195, Playa Palo Santa Rita,

La Paz, 23090, Baja California Sur, Mexico

E-mail: alopez@cibnor.mx

Tel.: + 52-11253633

Fax: $+52-11253625$

F. García-Pichel

Microbiology Department,

Arizona State University, Tempe, AZ 85287, USA

U. Nübel

Deutsche Sammlung von Mikroorganismen

und Zellkulturen, Mascheroder Weg 1B,

38124 Braunschweig, Germany 